\title{
Legacy Impacts of All-Time Anthropogenic Emissions on the Global Mercury Cycle
}

\section{Citation}

Amos, Helen Marie, Daniel James Jacob, David G. Streets, and Elsie M. Sunderland. 2013. "Legacy Impacts of All-Time Anthropogenic Emissions on the Global Mercury Cycle." Global Biogeochemical Cycles 27 (2): 410-421.

\section{Published Version}

doi: $10.1002 / g b c .20040$

\section{Permanent link}

http://nrs.harvard.edu/urn-3:HUL.InstRepos:13454554

\section{Terms of Use}

This article was downloaded from Harvard University's DASH repository, and is made available under the terms and conditions applicable to Open Access Policy Articles, as set forth at http:// nrs.harvard.edu/urn-3:HUL.InstRepos:dash.current.terms-of-use\#OAP

\section{Share Your Story}

The Harvard community has made this article openly available.

Please share how this access benefits you. Submit a story.

\section{Accessibility}




\title{
Legacy impacts of all-time anthropogenic emissions on the global mercury cycle
}

\author{
Helen M. Amos, ${ }^{1}$ Daniel J. Jacob, ${ }^{1,2}$ David G. Streets, ${ }^{3}$ and Elsie M. Sunderland ${ }^{2,4}$ \\ Received 6 November 2012; revised 28 February 2013; accepted 28 March 2013; published 9 May 2013.
}

[1] Elevated mercury $(\mathrm{Hg})$ in marine and terrestrial ecosystems is a global health concern because of the formation of toxic methylmercury. Humans have emitted $\mathrm{Hg}$ to the atmosphere for millennia, and this $\mathrm{Hg}$ has deposited and accumulated into ecosystems globally. Here we present a global biogeochemical model with fully coupled atmospheric, terrestrial, and oceanic $\mathrm{Hg}$ reservoirs to better understand human influence on $\mathrm{Hg}$ cycling and timescales for responses. We drive the model with a historical inventory of anthropogenic emissions from $2000 \mathrm{BC}$ to present. Results show that anthropogenic perturbations introduced to surface reservoirs (atmosphere, ocean, or terrestrial) accumulate and persist in the subsurface ocean for decades to centuries. The simulated present-day atmosphere is enriched by a factor of 2.6 relative to 1840 levels, consistent with sediment archives, and by a factor of 7.5 relative to natural levels (2000 BC). Legacy anthropogenic $\mathrm{Hg}$ re-emitted from surface reservoirs accounts for $60 \%$ of present-day atmospheric deposition, compared to $27 \%$ from primary anthropogenic emissions, and $13 \%$ from natural sources. We find that only $17 \%$ of the present-day $\mathrm{Hg}$ in the surface ocean is natural and that half of its anthropogenic enrichment originates from pre-1950 emissions. Although Asia is presently the dominant contributor to primary anthropogenic emissions, only $17 \%$ of the surface ocean reservoir is of Asian anthropogenic origin, as compared to $30 \%$ of North American and European origin. The accumulated burden of legacy anthropogenic $\mathrm{Hg}$ means that future deposition will increase even if primary anthropogenic emissions are held constant. Aggressive global $\mathrm{Hg}$ emission reductions will be necessary just to maintain oceanic $\mathrm{Hg}$ concentrations at present levels.

Citation: Amos, H. M., D. J. Jacob, D. G. Streets, and E. M. Sunderland (2013), Legacy impacts of all-time anthropogenic emissions on the global mercury cycle, Global Biogeochem. Cycles, 27, 410-421, doi:10.1002/gbc.20040.

\section{Introduction}

[2] Hg cycles naturally through geochemical reservoirs, but human activities such as mining and more recently fossil fuel combustion have been increasing the $\mathrm{Hg}$ flux from the deep mineral reservoir to the atmosphere for millennia [Nriagu, 1993, 1994; Lacerda, 1997; Camargo, 2002]. Here we present a global biogeochemical model of $\mathrm{Hg}$ that dynamically couples the ocean, atmosphere, and terrestrial reservoirs. We force the model with a historical inventory of anthropogenic emissions [Streets et al., 2011],

\footnotetext{
${ }^{1}$ Department of Earth and Planetary Sciences, Harvard University, Cambridge, Massachusetts, USA.

${ }^{2}$ School of Engineering and Applied Sciences, Harvard University, Cambridge, Massachusetts, USA.

${ }^{3}$ Decision and Information Sciences Division, Argonne National Laboratory, Argonne, Illinois, USA.

${ }^{4}$ Department of Environmental Health, Harvard School of Public Health, Boston, Massachusetts, USA.

Corresponding author: H. M. Amos, Department of Earth and Planetary Sciences, Harvard University, 29 Oxford St., Cambridge, MA 02138, USA. (amos@fas.harvard.edu)

(C)2013. American Geophysical Union. All Rights Reserved. 0886-6236/13/10.1002/gbc.20040
}

quantify the resulting present-day enrichment of the various global $\mathrm{Hg}$ reservoirs, and discuss implications for the future.

[3] Hg liberated from the deep mineral reservoir naturally (e.g., volcanoes) or by human activities cycles between the atmosphere and surface reservoirs (ocean and terrestrial ecosystems) on timescales of years to decades [Mason et al., 1994; Mason and Sheu, 2002; Selin et al., 2008]. It is eventually transferred to recalcitrant soil pools [SmithDowney et al., 2010] and the deep ocean [Gill and Fitzgerald, 1988; Sunderland and Mason, 2007] over centuries and back to the deep mineral reservoir over millennia [Andren and Nriagu, 1979]. Anthropogenic enrichment of the ocean is of particular interest because $\mathrm{Hg}$ exposure for most human populations is from methylmercury in marine fish [Johansen et al., 2004; Sunderland, 2007; Kim and Lee, 2010].

[4] Sedimentary and ice core records provide evidence of a two- to five-fold enrichment in present-day atmospheric $\mathrm{Hg}$ deposition relative to preindustrial (ca. 1840) levels [Fitzgerald et al., 1998; Schuster et al., 2002; Biester et al., 2007; Lindberg et al., 2007]. This reflects growing emissions in Europe and North America over the nineteenth and twentieth centuries, compounded by growth in Asian emissions over the past decades [Pacyna et al., 2003, 2006; 


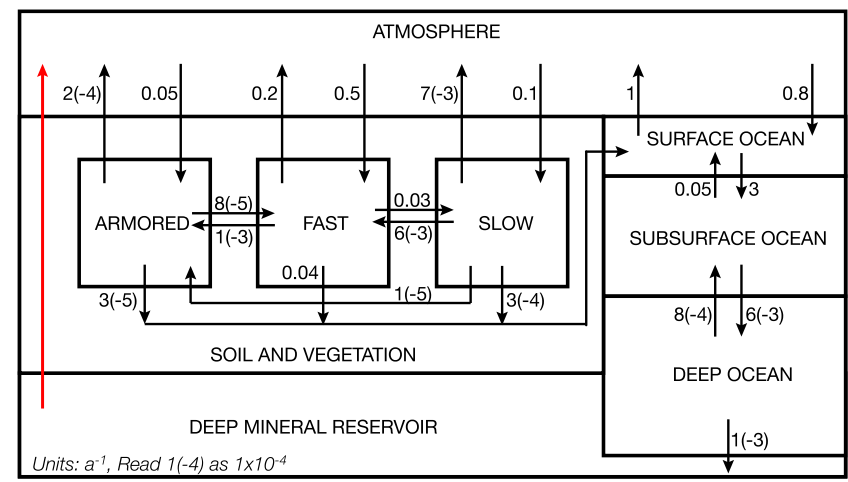

Figure 1. Rate coefficients $k_{i j}\left(\mathrm{a}^{-1}\right)$ driving our sevenreservoir global biogeochemical box model for $\mathrm{Hg} . k_{i j}$ defines the first-order transfer from reservoir $i$ to reservoir $j$ as $F_{i j}=k_{i j} m_{i}$, where $F_{i j}\left(\mathrm{Mg} \mathrm{a}^{-1}\right)$ is the Hg flow from reservoir $i$ to reservoir $j$ and $m_{i}(\mathrm{Mg})$ is the mass of $\mathrm{Hg}$ in reservoir $i$. Values of $k_{i j}$ are derived from best estimates of present-day flows and masses from the literature (Table 1) and are assumed to be constant in time. The red arrow represents the external forcing by primary emissions (geogenic or anthropogenic) from the deep mineral reservoir. Geogenic emissions are constant $\left(90 \mathrm{Mg} \mathrm{a}^{-1}\right)$, and anthropogenic emissions are time dependent (Figure 2).

Wu et al., 2006; Pacyna et al., 2010; Streets et al., 2011]. However, pre-1850 anthropogenic emissions were also large [Nriagu, 1993; Streets et al., 2011], as shown by long-term peat and sediment records [Roos-Barraclough et al., 2002, 2006; Cooke et al., 2009; Elbaz-Poulichet et al., 2011]. This historical anthropogenic $\mathrm{Hg}$ continues to cycle through biogeochemical reservoirs, representing a legacy of $\mathrm{Hg}$ enrichment in the environment.

[5] Understanding how the legacy of historical anthropogenic emissions impacts the present-day $\mathrm{Hg}$ cycle is necessary for projecting future changes. Global anthropogenic emissions are expected to increase in the future in the absence of directed efforts to control Hg [Streets et al., 2009]. The new global $\mathrm{Hg}$ treaty negotiated by the United Nations Environment Program (UNEP) aims to reduce anthropogenic sources [United Nations Environment Program (UNEP), 2013]. Here we examine how the global ocean, atmosphere, and terrestrial ecosystems will respond to future changes in emissions.

\section{Model Description}

[6] We develop a fully coupled, seven-reservoir box model of the global $\mathrm{Hg}$ cycle by building on previous models that focused on individual components of the cycle [Sunderland and Mason, 2007; Selin et al., 2008; Soerensen et al., 2010; Holmes et al., 2010; Smith-Downey et al., 2010]. Much of these previous works used the GEOS-Chem global 3-D model for atmospheric $\mathrm{Hg}$ coupled to 2-D surface reservoirs (http://geos-chem.org). Our seven-box model allows full coupling of the ocean, atmosphere, and terrestrial reservoirs for millennium-scale simulations. The seven reservoirs include the atmosphere, ocean (surface, subsurface, and deep), and terrestrial ecosystems (fast terrestrial, slow soil, and armored soil), as described below. $\mathrm{Hg}$ transferred from the deep mineral reservoir to the atmosphere by geogenic or anthropogenic emissions is viewed as an external forcing since the residence time of $\mathrm{Hg}$ in the deep mineral reservoir is $\sim 1$ billion years [Andren and Nriagu, 1979]. Burial from the deep ocean returns $\mathrm{Hg}$ to the deep mineral reservoir.

[7] Figure 1 provides a schematic of the box model. Mass transfer between model reservoirs is represented by a system of coupled first-order differential equations:

$$
\frac{\mathrm{d} \mathbf{m}}{\mathrm{d} t}=\mathbf{K m}+\mathbf{s}
$$

where $\mathbf{m}$ is a seven-element vector of reservoir masses $(\mathrm{Mg}$ of $\mathrm{Hg}), \mathbf{s}$ is a vector describing the external forcing $\left(\mathrm{Mg} \mathrm{a}^{-1}\right)$ from the deep mineral reservoir ( 0 for all reservoirs except for the atmosphere), and $\mathbf{K}$ is a $7 \times 7$ matrix of first-order time-invariant rate coefficients $k_{i j}\left(\mathrm{a}^{-1}\right)$ describing the flow from reservoir $i$ to reservoir $j$. Thus, $k_{i j}=F_{i j} / m_{i}$, where $F_{i j}$ $\left(\mathrm{Mg} \mathrm{a}^{-1}\right)$ is the flow (sink) from reservoir $i$ to reservoir $j$ and $m_{i}(\mathrm{Mg})$ is the mass of reservoir $i$. The flows are not thought to be limited by $\mathrm{Hg}$, so the assumption of firstorder behavior is reasonable. We derive values of $k_{i j}$ from literature estimates of present-day masses and flows, as summarized in Table 1 and described below. Estimates in Table 1 account for $\mathrm{Hg}$ speciation $(\mathrm{Hg}(0), \mathrm{Hg}(\mathrm{II})$, and particulate $\mathrm{Hg}$ ), but here we only track total $\mathrm{Hg}$.

[8] The physical and chemical processes driving the flows $F_{i j}$ are unlikely to have changed significantly over the Holocene, supporting the use of time-invariant $k_{i j}$. An exception may be the rate of atmospheric oxidation of $\operatorname{Hg}(0)$, which determines the rate coefficient for transfer from the atmosphere to the surface reservoirs $\left(1.5 \mathrm{a}^{-1}\right.$ in Figure 1, corresponding to an atmospheric lifetime of 8 months). Atmospheric oxidant levels may have been affected by human activities, but the resulting atmospheric lifetime of $\mathrm{Hg}$ is unlikely to have changed by more than a factor of 2 from present to preindustrial or over the Holocene [Thompson et al., 1993; Parrella et al., 2012] and is therefore short relative to the decadal and longer timescales of interest here. Changing the preindustrial atmospheric lifetime of $\mathrm{Hg}$ by a factor of 2 in our model has an inverse effect on the simulated atmospheric reservoir amount but has no effect on any other model results including the preindustrial-to-present enrichment factor for atmospheric deposition.

\subsection{Atmosphere}

[9] We adopt the present-day atmospheric reservoir and deposition estimates from the GEOS-Chem simulation of Holmes et al. [2010] (Table 1), which show no systematic biases against observations. The atmospheric reservoir is $5000 \mathrm{Mg}$, and the total deposition is $6900 \mathrm{Mg} \mathrm{a}^{-1}$, corresponding to an atmospheric lifetime of 0.7 years. Other literature estimates give a range of $4600-5600 \mathrm{Mg}$ for the atmospheric reservoir, $4200-9000 \mathrm{Mg} \mathrm{a}^{-1}$ for total deposition, and 0.5-1.5 years for atmospheric lifetime [Slemr et al., 1985; Lindqvist and Rodhe, 1985; Mason et al., 1994; Shia et al., 1999; Mason and Sheu, 2002; Lamborg et al., 2002b; Seigneur et al., 2004; Selin et al., 2008; Amos et al., 2012]. 
Table 1. Present-Day Hg Reservoirs and Flows ${ }^{\mathrm{a}}$

\begin{tabular}{|c|c|}
\hline & Flows $\left(\mathrm{Mg} \mathrm{a}^{-1}\right)$ \\
\hline \multicolumn{2}{|l|}{ Atmosphere: $5000 \mathrm{Mg}$} \\
\hline $\mathrm{Hg}(\mathrm{II})$ deposition to ocean & 3900 \\
\hline $\mathrm{Hg}(0)$ deposition to ocean & 40 \\
\hline $\mathrm{Hg}(\mathrm{II})$ deposition to land ${ }^{\mathrm{b}}$ & 1500 \\
\hline $\mathrm{Hg}(0)$ deposition to land $\mathrm{c}^{\mathrm{c}}$ & 1500 \\
\hline \multicolumn{2}{|l|}{ Surface ocean ${ }^{\mathrm{d}}: 2900 \mathrm{Mg}$} \\
\hline $\mathrm{Hg}(0)$ evasion & 3000 \\
\hline Particle settling to subsurface ocean & 3300 \\
\hline Water transfer to subsurface ocean & 5100 \\
\hline \multicolumn{2}{|l|}{ Subsurface ocean ${ }^{\mathrm{e}}: 130,000 \mathrm{Mg}$} \\
\hline Particle settling to deep ocean & 480 \\
\hline Water transfer to surface ocean & 7100 \\
\hline Water transfer to deep ocean & 340 \\
\hline \multicolumn{2}{|l|}{ Deep ocean: $220,000 \mathrm{Mg}$} \\
\hline Burial to deep sediments & 210 \\
\hline Water transfer to subsurface ocean & 180 \\
\hline \multicolumn{2}{|l|}{ Fast terrestrial pool: $9600 \mathrm{Mg}$} \\
\hline Evasion due to respiration of organic carbon & 460 \\
\hline Photochemical re-emission of deposited $\mathrm{Hg}$ & 850 \\
\hline Biomass burning $^{\mathrm{f}}$ & 290 \\
\hline Transfer to slow pool & 330 \\
\hline Transfer to armored pool & 10 \\
\hline River runoff to surface ocean ${ }^{\mathrm{g}}$ & 365 \\
\hline \multicolumn{2}{|l|}{ Slow soil pool: $35,000 \mathrm{Mg}$} \\
\hline Evasion due to respiration of organic carbon & 250 \\
\hline Biomass burning & 8 \\
\hline Transfer to fast pool & 210 \\
\hline River runoff to surface ocean & 10 \\
\hline \multicolumn{2}{|l|}{ Armored soil pool: $190,000 \mathrm{Mg}$} \\
\hline Evasion due to respiration of organic carbon & 25 \\
\hline Biomass burning & 4 \\
\hline Transfer to fast pool & 15 \\
\hline River runoff to surface ocean & 5 \\
\hline \multicolumn{2}{|l|}{ Deep mineral reservoir: $3 \times 10^{11} \mathrm{Mg}$} \\
\hline Geogenic emission & 90 \\
\hline Anthropogenic emissions ${ }^{\mathrm{h}}$ & 2000 \\
\hline
\end{tabular}

${ }^{\mathrm{a}}$ The best estimates of present-day reservoirs $m_{l}$ and flows $F_{i j}$ given in this table are used to derive the rate coefficients $k_{i j}=\mathrm{F}_{\mathrm{ij}} / m_{i}$ in Figure 1. References are Holmes et al. [2010] for the atmosphere and biomass burning, Soerensen et al. [2010] for the surface ocean, Sunderland and Mason [2007] for the subsurface/deep ocean and river runoff, Smith-Downey et al. [2010] for the terrestrial/soil pools, and Andren and Nriagu [1979] and Pirrone et al. [2010] for the deep mineral reservoir.

${ }^{\mathrm{b}}$ Partitioned $50 \%$ to the fast terrestrial pool, $32 \%$ to the slow soil pool, and $18 \%$ to the armored soil pool following Smith-Downey et al. [2010].

${ }^{\mathrm{c}} \mathrm{All} \mathrm{Hg}(0)$ deposition is delivered to the fast terrestrial pool.

${ }^{\mathrm{d}}$ Extending down to the base of the ocean mixed layer.

${ }^{\mathrm{e}}$ Extending from the base of the ocean mixed layer down to the depth of the permanent thermocline.

${ }^{\mathrm{f}}$ Total biomass burning is $300 \mathrm{Mg} \mathrm{a}^{-1}$ [Holmes et al., 2010] and is apportioned as $95 \%$ from vegetation (fast terrestrial pool) and 5\% from the three soil pools (fast, slow, and armored) based on carbon content [Smith-Downey et al., 2010].

${ }^{\mathrm{g}}$ Total river runoff is $380 \mathrm{Mg} \mathrm{a}^{-1}$ [Sunderland and Mason, 2007] and is partitioned among the soil pools in the same manner as biomass burning.

${ }^{\mathrm{h}}$ Anthropogenic emissions are time dependent (see Figure 2a). The value $2000 \mathrm{Mg} \mathrm{a}^{-1}$ corresponds to the year 2008 from Streets et al. [2011].

\subsection{Ocean}

[10] We partition the ocean into three reservoirs: (1) the surface ocean extending to the base of the mixed layer, (2) the subsurface ocean extending to the depth of the permanent thermocline $(1500 \mathrm{~m}$ based on Sunderland and Mason [2007]), and (3) the deep ocean extending to the sea floor. Our surface ocean budget, including air-sea exchange, is based on the GEOS-Chem simulation of Soerensen et al. [2010], which uses a global mean mixed layer depth of $54 \mathrm{~m}$ based on observations [Montegut et al., 2004]. Subsurface and deep ocean reservoirs are estimated from vertical $\mathrm{Hg}$ profile data following Sunderland and Mason [2007].

[11] Hg flows/sinks from ocean reservoirs include evasion to the atmosphere, settling of particulate matter including eventual burial in deep-sea sediments, and vertical transport of seawater. Particle settling is based on carbon export fluxes (ocean rain) using the parameterization of Antia et al. [2001] and global ocean productivity from Moderate Resolution Imaging Spectroradiometer (MODIS) satellite data (see Soerensen et al. [2010] and Sunderland and Mason [2007] for details). Burial to deep ocean sediments returns $\mathrm{Hg}$ to the deep mineral reservoir. Sunderland and Mason [2007] estimated the present-day range in burial to be $180-260 \mathrm{Mg} \mathrm{a}^{-1}$. Model results are relatively insensitive $(<10 \%)$ to this range.

\subsection{Terrestrial Ecosystems}

[12] Terrestrial $\mathrm{Hg}$ is partitioned into three reservoirs based on the Global Terrestrial Mercury Model (GTMM) of SmithDowney et al. [2010]: fast terrestrial reservoir, slow soil, and armored soil. The fast terrestrial reservoir includes vegetation, litter, labile organic carbon soil pools, and ice and snowcovered terrestrial surfaces [Smith-Downey et al., 2010]. Slow and armored soil pools are defined by long turnover times for organic carbon mineralization, with armored soils being the most recalcitrant. GTMM is based on the association of $\mathrm{Hg}$ with organic carbon and uses soil carbon pools and turnover times from the Carnegie Ames Standford Approach (CASA) biogeochemical model for carbon [Potter et al., 1993; van der Werf et al., 2003].

[13] Hg from terrestrial reservoirs is transferred to the atmosphere by respiration of organic carbon, photoreduction, and biomass burning; and to the surface ocean by river runoff. $\mathrm{Hg}$ emissions associated with organic carbon decomposition $\left(740 \mathrm{Mg} \mathrm{a}^{-1}\right)$ are from Smith-Downey et al. [2010]. Global estimates of photoreduction are in the range $260-1100 \mathrm{Mg} \mathrm{a}^{-1}$ [Selin et al., 2008; Smith-Downey et al., 2010; Holmes et al., 2010]. We adopt a value of $850 \mathrm{Mg} \mathrm{a}^{-1}$ to balance emissions and deposition in our atmospheric budget. Global biomass burning emission estimates range from 300 [Holmes et al., 2010] to $675 \mathrm{Mg} \mathrm{a}^{-1}$ [Friedli et al., 2009]. We use $300 \mathrm{Mg} \mathrm{a}^{-1}$ here, but a larger biomass burning source could be equivalently accommodated in our model by decreasing the photoreduction source. We assume that $95 \%$ of the biomass burning source is from the fast terrestrial reservoir (which includes vegetation), and the remaining $5 \%$ is partitioned among the fast, slow, and armored soils based on their respective soil organic carbon content, following Smith-Downey et al. [2010]. River runoff is $380 \mathrm{Mg} \mathrm{a}^{-1}$ from Sunderland and Mason [2007] and is partitioned among terrestrial pools in the same manner as biomass burning.

\subsection{Geogenic Emission}

[14] We define geogenic emission as $\mathrm{Hg}$ liberated from the deep mineral reservoir by volcanic activity, crustal degassing, and weathering [Nriagu and Becker, 2003]. Andren and Nriagu [1979] estimated the size of the deep mineral reservoir to be $3 \times 10^{11} \mathrm{Mg}$. Estimates of geogenic range from $\sim 1$ to $1000 \mathrm{Mga}^{-1}$ [Varekamp and Buseck, 1986; Ferrara et al., 2000; Nriagu and Becker, 2003; Pyle and Mather, 2003; Bagnato et al., 2011], but little confidence is placed in the extrema of this range [Pyle and 
(a) Primary Anthropogenic Emissions

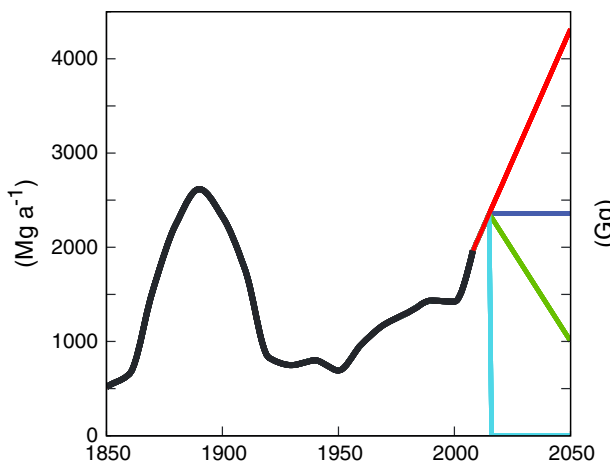

(c) Atmospheric Deposition

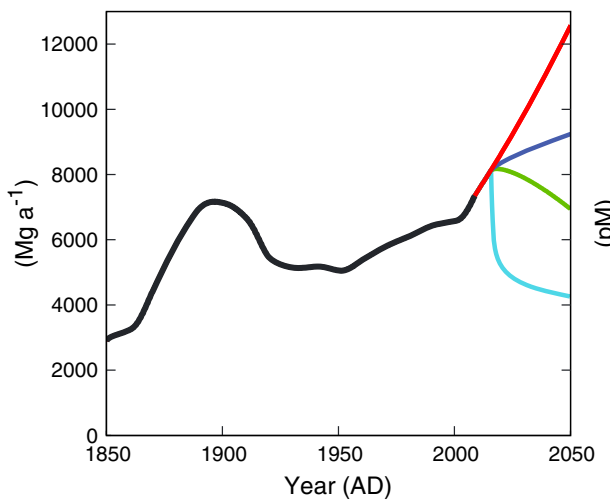

(b) Cumulative Emissions

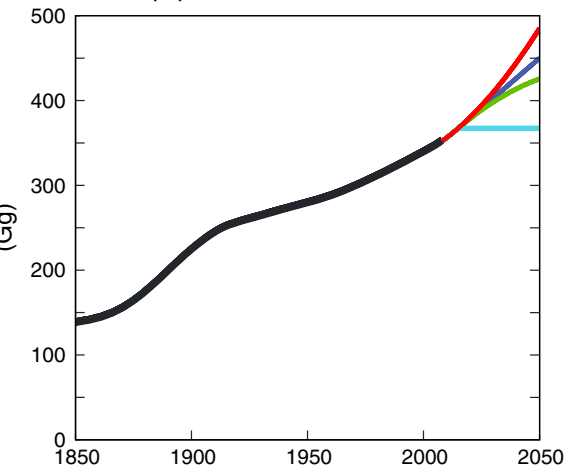

(d) Ocean Mercury Concentration

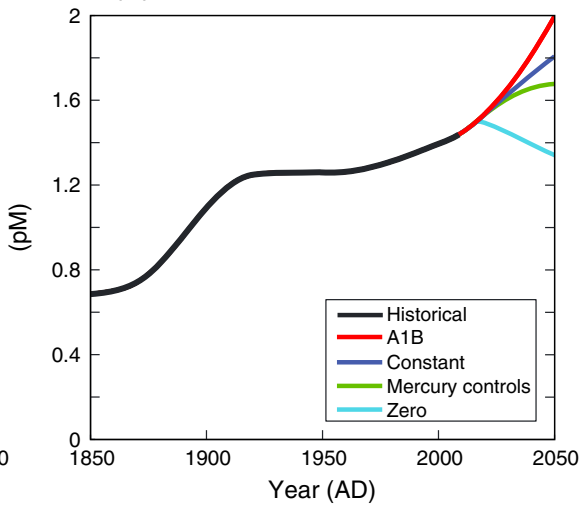

Figure 2. History of global anthropogenic influence on environmental Hg: (a) primary anthropogenic emissions to the atmosphere, (b) corresponding cumulative emissions, (c) atmospheric deposition, and (d) combined surface + subsurface ocean mercury concentrations. The 1850-2008 emissions are from Streets et al. [2011]. Pre-1850 emissions are as described in the text. Post-2008 emissions assume the business-as-usual A1B scenario of Streets et al. [2009] from 2008 to 2015 and different hypothetical emission trajectories afterward as described in the text.

Mather, 2003; Bagnato et al., 2011]. We use $90 \mathrm{Mga}^{-1}$ from Pirrone et al. [2010], which is consistent with the estimate of Bagnato et al. [2011] $\left(95 \mathrm{Mg} \mathrm{a}^{-1}\right)$ derived from atmospheric observations of volcanic plumes.

\subsection{Anthropogenic Emissions}

[15] We force the model from $2000 \mathrm{BC}$ to $2008 \mathrm{AD}$ with primary anthropogenic emissions of total $\mathrm{Hg}$, as shown in Figure 2a. "Primary" refers to direct transfer from the deep mineral reservoir to the atmosphere. Streets et al. [2011] gave a best estimate of $2000 \mathrm{Mga}^{-1}$ for 2008 emissions (referred to here as "present-day"), a total of $215 \mathrm{Gg}$ for 1850-2008 emissions with decadal information on emission sectors and source regions, and a pre-1850 total of $137 \mathrm{Gg}$ without temporal information. Based on the work of Nriagu [1993] and Streets et al. [2011], we estimate that $111 \mathrm{Gg}$ of that total was emitted between 1570 and 1850, mainly in association with silver mining in Spanish America. The remaining $26 \mathrm{Gg}$ is emitted before $1570 \mathrm{AD}$.

[16] Sediment cores [Cooke et al., 2009; Elbaz-Poulichet et al., 2011] and archeological evidence [Goldwater, 1972 and references therein; Nriagu, 1979 and references therein] suggest more than 3500 years of $\mathrm{Hg}$ releases from human activity. We initiate anthropogenic $\mathrm{Hg}$ emissions in $2000 \mathrm{BC}$ based on use of $\mathrm{Hg}$ as pigment as far back as 2500 $1600 \mathrm{BC}$ by the Greeks, reports of quicksilver found in a tomb dating to $\sim 2000 \mathrm{BC}$, and use of $\mathrm{Hg}$ (as quicksilver and cinnabar) by the Assyrians as early as $1900 \mathrm{BC}$ [Goldwater, 1972]. We assume a linear increase in emissions from $2000 \mathrm{BC}$ until $1570 \mathrm{AD}$, a step increase at $1570 \mathrm{AD}$ due to silver production in Spanish America [Nriagu, 1993, 1994; Camargo, 2002], and constant emissions between 1570 and $1850 \mathrm{AD}$. Model results are insensitive to the details of this emission schedule, as discussed in section 3 .

[17] Streets et al. [2009] projected future $\mathrm{Hg}$ emissions out to 2050 using the International Panel on Climate Change (IPCC) Special Report on Emissions Scenarios (SRES) scenarios [Nakicenovic, 2000]. The A1B business-as-usual scenario features continued growth in emissions such that primary anthropogenic emissions in 2050 are a factor of 3.6 higher than present-day. The most optimistic SRES scenario (B1) has effectively constant emissions relative to present-day levels [Streets et al., 2009]. These scenarios assume no direct policy intervention for $\mathrm{Hg}$ control, but some level of intervention may be anticipated in light of the recent $\mathrm{Hg}$ treaty negotiated by UNEP [UNEP, 2013]. To illustrate the potential benefit of emission controls, we consider a "mercury controls" scenario where primary anthropogenic emissions decline by 2050 to $50 \%$ of their present-day value. Achieving this level of reduction would require implementation of Hg-specific control technologies across multiple sectors (fuel combustion, mining, waste incineration, and 
Table 2. Hg Reservoir Masses and Historical Anthropogenic Enrichments

\begin{tabular}{|c|c|c|c|c|c|}
\hline \multirow[b]{2}{*}{ Reservoir } & \multicolumn{3}{|c|}{ Reservoir Mass (Mg) } & \multicolumn{2}{|c|}{ Enrichment Factor } \\
\hline & Natural & $\begin{array}{l}\text { Preindustrial } \\
\quad(1840)\end{array}$ & $\begin{array}{l}\text { Present } \\
\text { Day }\end{array}$ & $\begin{array}{c}\text { All } \\
\text { Time }^{\mathrm{a}}\end{array}$ & Modern $^{\mathrm{b}}$ \\
\hline $\begin{array}{l}\text { Atmosphere } \\
\text { Terrestrial }\end{array}$ & 700 & 2,000 & 5,300 & 7.5 & 2.6 \\
\hline Fast & 1,900 & 4,800 & 11,000 & 5.8 & 2.3 \\
\hline Slow & 9,800 & 24,000 & 50,000 & 5.1 & 2.1 \\
\hline $\begin{array}{l}\text { Armored } \\
\text { Ocean }\end{array}$ & 170,000 & 180,000 & 210,000 & 1.2 & 1.1 \\
\hline Surface & 530 & 1,300 & 3,100 & 5.9 & 2.3 \\
\hline Subsurface & 26,000 & 67,000 & 140,000 & 5.3 & 2.1 \\
\hline Deep & 95,000 & 130,000 & 200,000 & 2.1 & 1.5 \\
\hline
\end{tabular}

${ }^{a}$ Ratio of present-day to natural reservoir mass.

${ }^{\mathrm{b}}$ Ratio of present-day to preindustrial (1840) reservoir mass.

industry). We also consider a "zero emissions" scenario where primary anthropogenic emissions are completely eliminated as of 2015. This bounds the maximum achievable global benefit from regulating emissions. Business-as-usual is assumed between 2008 and 2015, and all scenarios take effect in 2015.

\section{Historical Reconstruction and Uncertainty}

\subsection{Historical Reconstruction and Model Evaluation}

[18] We first apply the model to simulate natural steady state conditions, defined by solving (1) for $\mathrm{d} \mathbf{m} / \mathrm{d} t=\mathbf{0}$ with $\mathbf{s}=90 \mathrm{Mg} \mathrm{a}^{-1}$ as the constant geogenic source. Table 2 shows the resulting natural distribution of $\mathrm{Hg}$ between reservoirs. From this initial condition, we force the model with historical anthropogenic emissions (2000 BC-present), shown in Figure 2a. Table 2 shows the resulting preindustrial (1840) and present-day reservoir masses.

[19] Figure 3 depicts our simulated present-day global budget. Reservoir masses and flows are comparable to the literature values of Table 1 used to construct the model, even though these literature values were used only to constrain the first-order rate coefficients in the model. This demonstrates consistency between present-day anthropogenic enrichments and our historical inventory of anthropogenic emissions. It provides an independent check because we do not impose a preindustrial-to-present enrichment in atmospheric deposition unlike previous reconstructions [Mason et al., 1994; Mason and Sheu, 2002; Seigneur et al., 2004; Selin et al., 2008; Smith-Downey et al., 2010]. The present-day
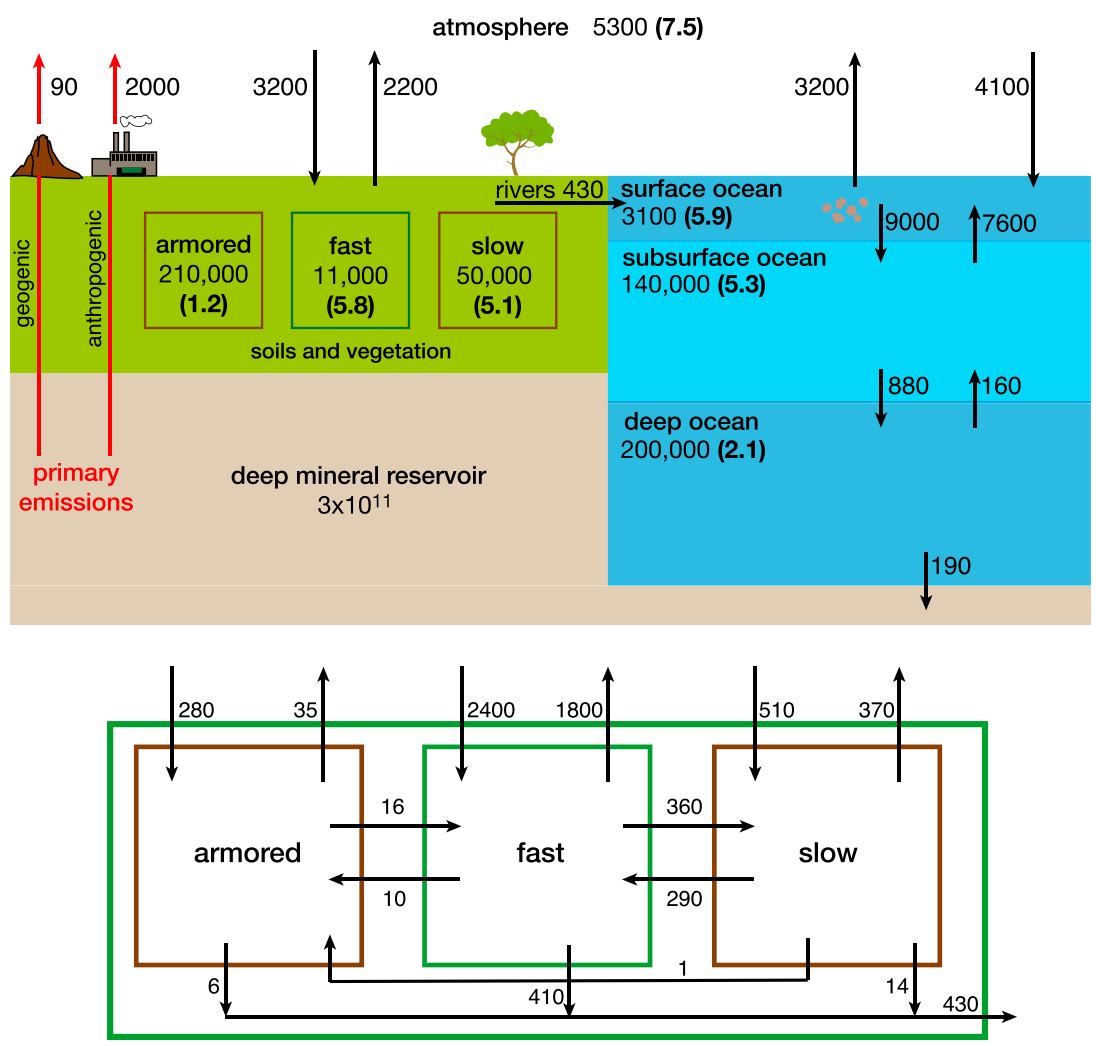

Reservoirs in $\mathrm{Mg}$, flows in $\mathrm{Mg} \mathrm{a}^{-1}$

( ) indicate all-time anthropogenic enrichment factors

Figure 3. Simulated present-day global $\mathrm{Hg}$ budget and all-time anthropogenic enrichments factors. Terrestrial-atmosphere exchange is given in the top panel for the sum of terrestrial reservoirs. The bottom panel shows the breakdown and cycling between the different terrestrial reservoirs. All terrestrial reservoirs receive inputs from $\mathrm{Hg}(\mathrm{II})$ deposition (fast $=800$, slow $=510$, and armored $=280 \mathrm{Mg} \mathrm{a}^{-1}$ ). The fast reservoir also receives inputs from $\mathrm{Hg}(0)$ deposition $\left(1600 \mathrm{Mg} \mathrm{a}^{-1}\right)$. All terrestrial reservoirs lose $\mathrm{Hg}$ through respiration (fast $=520$, slow $=360$, and armored $=30 \mathrm{Mg} \mathrm{a}^{-1}$ ) and biomass burning (fast $=320$, slow $=9$, and armored $\left.=5 \mathrm{Mg} \mathrm{a}^{-1}\right)$. Photoreduction from the fast terrestrial reservoir is $950 \mathrm{Mg} \mathrm{a}^{-1}$. 
atmospheric $\mathrm{Hg}$ reservoir is simulated to be $5300 \mathrm{Mg}$, within the range of 4600-5600 Mg constrained by observations (see section 2.1). The mean ocean concentration above the thermocline (surface + subsurface) is $1.4 \mathrm{pM}$, consistent with the range of $0.5-2.5 \mathrm{pM}$ given by Mason et al. [2012] from compiled observations. We find a modern (preindustrial-topresent) enrichment factor of 2.6 for atmospheric deposition, which is consistent with sediment core data, indicating that atmospheric $\mathrm{Hg}$ deposition has increased by 2 to 5 times relative to preindustrial levels [Lamborg et al., 2002a; Biester et al., 2007; Drevnick et al., 2012]. We conclude that our box model provides a realistic representation of the present-day budget of $\mathrm{Hg}$ in the different geochemical reservoirs and a plausible reconstruction of the historical anthropogenic enrichment.

\subsection{Uncertainty in Natural Processes}

[20] We applied perturbation analysis to examine how uncertainties in individual model terms affect simulated anthropogenic enrichments of the different $\mathrm{Hg}$ reservoirs, using the three observational constraints defined above: (1) present-day atmospheric reservoir $(4600-5600 \mathrm{Mg})$, (2) present-day surface + subsurface ocean concentration (0.5-2.5 pM), and (3) preindustrial-to-present enrichment factor in atmospheric deposition (2-5). We find that the simulated preindustrial-to-present enrichment factor is most sensitive to uncertainties in geogenic emissions and oceanic evasion. The magnitude of geogenic emissions dictates the natural $\mathrm{Hg}$ loading and the resulting relative enrichment from primary anthropogenic emissions. Based on the observational constraints and reasonable estimates for primary anthropogenic emissions, geogenic emissions are unlikely to be more than 4 times larger than our adopted value of $90 \mathrm{Mg} \mathrm{a}^{-1}$ and could be smaller. Larger geogenic emissions decrease the relative anthropogenic enrichment and vice versa.

[21] Oceanic evasion is the largest single input of $\mathrm{Hg}$ to the atmosphere and is a major removal pathway of $\mathrm{Hg}$ from the surface ocean (Table 1 and Figure 3). Qureshi et al. [2011] highlighted the uncertainty in ocean evasion and its influence on the global biogeochemical cycle of $\mathrm{Hg}$. Removal of $\mathrm{Hg}$ from the surface ocean is a competitive process between evasion and export to the subsurface ocean by particle scavenging. If evasion rates decrease, the net transfer to the subsurface ocean increases while atmospheric deposition decreases, and there is an associated increase in the relative anthropogenic enrichment of atmospheric deposition. To be consistent with both the present-day atmospheric reservoir and the preindustrial-to-present enrichment in atmospheric deposition, we find that the rate coefficient of ocean evasion in our model must be within $\pm 30 \%$ of our best estimate from Figure 1.

[22] Perturbations to the rate coefficients for terrestrial cycling have less effect on our model results than geogenic emissions or oceanic evasion, in terms of the three observational constraints above. This is because, as discussed below, $\mathrm{Hg}$ perturbations to surface reservoirs propagate principally to the ocean. We see from Figure 3 that the terrestrial reservoirs are only weakly coupled to one another and instead exchange principally with the atmosphere. However, such a result is contingent on the mechanistic basis for our terrestrial $\mathrm{Hg}$ model that presumes a strong association of $\mathrm{Hg}$ with organic matter [SmithDowney et al., 2010]. Better understanding of terrestrial cycling of $\mathrm{Hg}$ is needed.

\subsection{Uncertainty in Anthropogenic Emissions}

[23] Streets et al. [2011] gave uncertainties in the range of $-30 \%$ to $+60 \%$ for $1920-2008$ anthropogenic emissions, with somewhat larger uncertainties before 1920. We estimate an uncertainty range of $-50 \%$ and $+300 \%$ for pre1850 emissions, with additional uncertainty in the timing of these emissions. We conducted sensitivity simulations to investigate the effect of these uncertainties using the same three observational constraints as above to guide the analysis. We find that the timing and initiation (between 2000 and $500 \mathrm{BC}$ ) of pre-1570 anthropogenic emissions has no significant effect on model results because these emissions are small (best estimate of $26 \mathrm{Gg}$ ) and the associated $\mathrm{Hg}$ has been transferred by now to the deep ocean, armored soil, and deep mineral reservoir. Simulated all-time enrichment and the present-day budget (Figure 3 ) are also insensitive $(<5 \%)$. We find also little sensitivity to the timing of 1570-1850 AD anthropogenic emissions. The simulated preindustrial-to-present enrichment in atmospheric deposition decreases from a factor of 2.6 to 2.4 if the timing is shifted (based on Nriagu [1993]) to release $70 \%$ of these emissions during 1700-1850 AD rather than 50\%.

[24] The magnitude of all-time anthropogenic emissions has more impact on model results. We conducted sensitivity simulations following the lower or upper envelope of the historical range of emission uncertainties (see above). The resulting ranges for the lower-upper envelope of emissions are $4100-9000 \mathrm{Mg}$ for the present-day atmospheric reservoir, 1.1-2.6 pM for the present-day surface + subsurface ocean concentration, and 2.9-2.0 for the preindustrial-topresent enrichment factor in atmospheric deposition. The upper envelope is unrealistic, as reflected by its large overestimate of the present-day atmospheric reservoir. The lower envelope is within the uncertainty of observational constraints and will be used below to provide a lower limit on anthropogenic influence (section 5). The all-time anthropogenic emissions for the lower envelope amount to $232 \mathrm{Gg}$, as compared to $352 \mathrm{Gg}$ for our best estimate.

\section{Timescales for Hg Cycling and Response to Perturbations}

\subsection{Eigenanalysis of Characteristic Timescales}

[25] Understanding the timescales involved in $\mathrm{Hg}$ biogeochemical cycling is critical to interpreting the effects of anthropogenic perturbations. Residence times $\tau_{i}=1 / \sum_{j} k_{i j}$ for individual reservoirs in our seven-box model provide a first estimate of these timescales but do not account for the coupling between reservoirs. Eigenanalysis of the $7 \times 7$ mass transfer matrix $\mathbf{K}=\left(k_{i j}\right)$ in equation (1) identifies the true timescales of the coupled system [Prather, 1996]. Each eigenvector $\mathbf{x}_{p}(p \in[1,7])$ with eigenvalue $\lambda_{p}$ represents a normal mode of the model, and any perturbation to that mode decays exponentially with a characteristic timescale $-1 / \lambda_{p}$. 


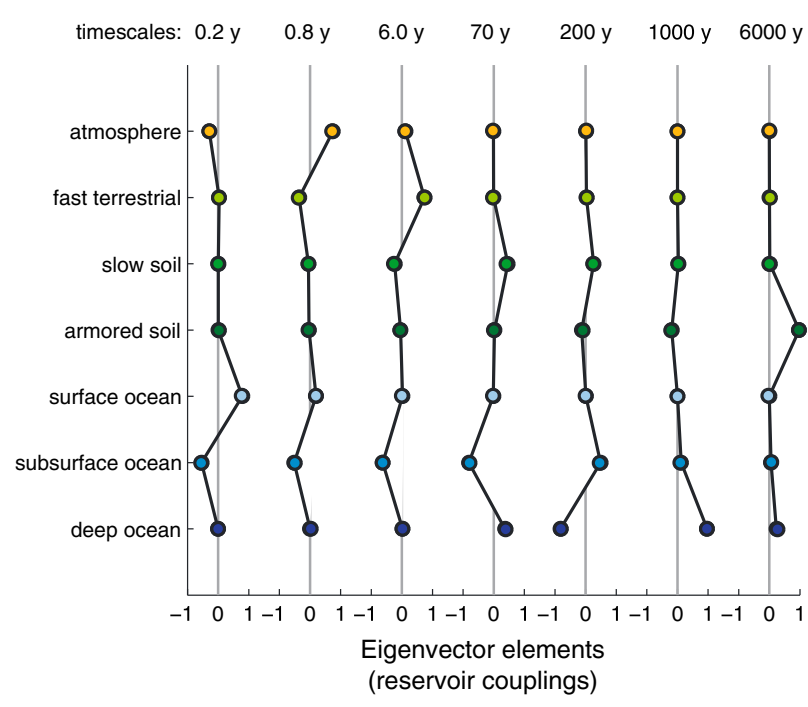

Figure 4. Normal modes of the Hg biogeochemical model. Each column describes an eigenvector of the mass transfer matrix $\mathbf{K}$ and represents a normal mode of the system. Perturbation to a normal mode decays exponentially with a timescale equal to the inverse of the corresponding eigenvalue. These timescales are displayed above the modes. The elements of the eigenvectors indicate the coupling between reservoirs associated with each timescale. For example, Mode 1 ( 0.2 years) describes a strong coupling between the surface and subsurface ocean reservoirs, and a weak coupling with the atmosphere. Mode 2 ( 0.8 years) describes a strong coupling between the atmosphere and subsurface ocean. Figure 5 gives a schematic summary of the information in this figure, highlighting the dominant couplings associated with each mode.

[26] Figure 4 shows the normal modes of our model and the corresponding characteristic timescales. Any initialtime perturbation $\Delta \mathbf{m}(0)$ to the model can be projected on the basis of these normal modes as

$$
\Delta \mathbf{m}(0)=\sum_{p=1}^{7} \alpha_{p} \mathbf{x}_{p}
$$

where $\alpha_{p}$ are coefficients. Thus, the perturbation decays as a sum of exponentials following

$$
\Delta \mathbf{m}(t)=\sum_{p=1}^{7} \alpha_{p} \mathbf{x}_{p} \exp \left[\lambda_{p} t\right]
$$

where the eigenvalues $\lambda_{p}$ must be real and negative for the system to show stable behavior. Different perturbations will excite different combinations of modes (and hence reservoir couplings). The eigenlifetimes $-1 / \lambda_{p}$ are the true timescales describing the dynamics of the model.

[27] Each mode in Figure 4 is defined by its eigenvector elements, describing the nature of the coupling between reservoirs for the corresponding timescale. Although all reservoirs are coupled on any of the timescales, there is always a dominant pair as is highlighted in the simplified schematic of Figure 5, which summarizes the information contained in Figure 4 . The shortest mode, Mode $1\left(-1 / \lambda_{1}=0.2\right.$ years), principally describes the fast exchange between the surface and subsurface ocean. Mode 2 (0.8 years) describes the coupling between the atmosphere and subsurface ocean via the surface ocean. Modes 3 (6 years) and 4 (70 years) couple respectively the fast and slow terrestrial pools to the subsurface ocean via the atmosphere and surface ocean. Mode 5 (200 years) couples the subsurface and deep ocean by vertical seawater mixing. Mode 6 (1000 years) describes the return of $\mathrm{Hg}$ to the deep mineral reservoir by burial from the deep ocean. Mode 7 (6000 years) describes the ultimate decay of the perturbation by transfer from the armored soil reservoir to the deep mineral reservoir via ocean burial.

[28] The subsurface ocean is known to be central in driving the biogeochemical Hg cycle [Mason et al., 1994; Mason and Sheu, 2002; Sunderland and Mason, 2007; Mason et al., 2012; Soerensen et al., 2012], and this is apparent in Figure 5. We see from Figure 5 that the subsurface ocean is coupled to the atmosphere via deposition and air-sea exchange ( 0.8 years), to the fast and slow terrestrial reservoirs via river runoff and atmospheric cycling (6-70 years), and to the deep ocean (200 years) from which $\mathrm{Hg}$ is eventually buried in deep-sea sediments. We also see from Figures 4 and 5 that the different terrestrial reservoirs are only weakly coupled between themselves and instead exchange $\mathrm{Hg}$ principally through the atmosphere-ocean system, emphasizing again the role of the subsurface ocean.

\subsection{Fate of $\mathbf{H g}$ Released in Surface Reservoirs}

[29] Figure 6 illustrates the fate of a pulse of $\mathrm{Hg}$ released in different surface reservoirs as computed from our box model. Here a unit pulse of $\mathrm{Hg}$ is released at time $t=0$ in the atmosphere (top panel), the fast terrestrial reservoir (middle panel), or the surface ocean (bottom panel), with no further releases for $t>0$. We find that the pulse is

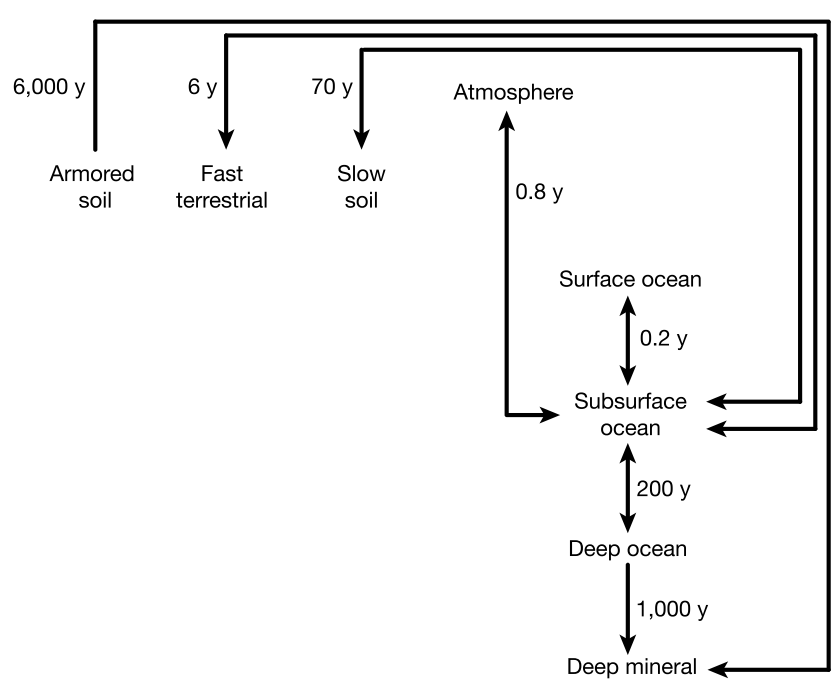

Figure 5. Characteristic timescales (years) for $\mathrm{Hg}$ biogeochemical cycling derived from eigenanalysis of our sevencompartment box model (see section 4.1). The arrows indicate the principal reservoirs coupled over each timescale. These couplings often involve a combination or succession of transfers through intermediate reservoirs. More details are presented in Figure 4. 

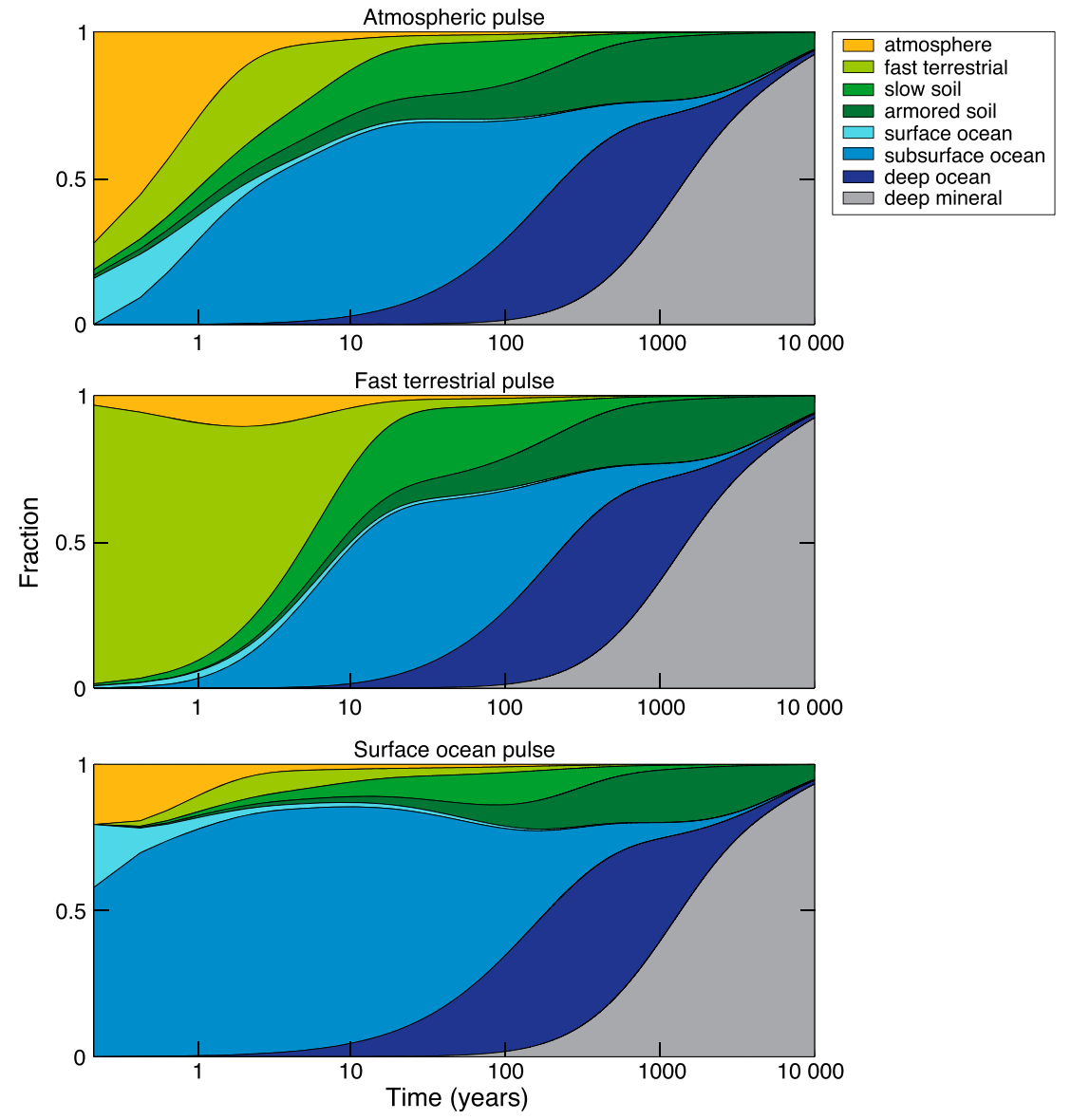

Figure 6. Time-dependent rate of a pulse of $\mathrm{Hg}$ released to the atmosphere (top), fast terrestrial pool (middle), or surface ocean (bottom). A unit pulse of $\mathrm{Hg}$ is injected into the corresponding reservoir at time $t=0$ years, and the resulting mass fraction from that pulse in individual reservoirs is plotted as a function of time. Note the log scale for time.

transferred away from the reservoir of origin on a timescale of months (surface ocean and atmosphere) to a decade (fast terrestrial). In all three cases, the transfer of $\mathrm{Hg}$ is principally to the subsurface ocean due to the fast timescales coupling the subsurface ocean to all three surface reservoirs (Figure 5).

[30] Even when the initial release is to the fast terrestrial reservoir, we find that most of the $\mathrm{Hg}$ ends up in the subsurface ocean on a timescale of a decade. In our model, terrestrial $\mathrm{Hg}$ can be transferred to the surface ocean either by re-emission to the atmosphere (photoreduction, respiration of organic matter, and biomass burning) and subsequent deposition, or by river runoff. Cycling through the atmosphere is the dominant pathway (Figure 3). Transfer of $\mathrm{Hg}$ from the fast terrestrial reservoir to more recalcitrant soil pools is slow in comparison.

[31] Even though the armored soil is the dominant $\mathrm{Hg}$ reservoir under natural (i.e., steady state) conditions (Table 2), we find that a $\mathrm{Hg}$ perturbation to the surface reservoirs propagates principally to the ocean. Regardless of the location of the pulse of origin, after 1000 years, we find that $40 \%$ is in the ocean, $20 \%$ is in the soil, and $40 \%$ has been returned to the deep mineral reservoir (Figure 6). The preferential long-lived reservoir for the perturbed system is the deep ocean, imposing a continued legacy on the subsurface/surface ocean reservoirs through vertical exchange of seawater. The implication of our work is that in the decades following release to the atmosphere, surface ocean, or terrestrial ecosystem, a large fraction of anthropogenic $\mathrm{Hg}$ will end up in the subsurface ocean.

\section{Anthropogenic Enrichment and the Importance of Legacy $\mathbf{H g}$}

[32] Table 2 shows that the present-day anthropogenic enrichment of the surface and subsurface ocean is similar to that in the atmosphere, reflecting the short timescales for coupling of these reservoirs. Even the deep ocean shows a factor of 2 enrichment. We find that the present-day atmospheric $\mathrm{Hg}$ reservoir (and deposition) is enriched 7.5 times relative to natural levels (Table 2 and Figure 3). Modeled enrichment is still 5.8 for the lower bound of anthropogenic emissions (section 3.3). This enrichment is larger than the observed three-fold anthropogenic enrichment from sediment cores that extend back to the mid-nineteenth century [Biester et al., 2007; Lindberg et al., 2007] and reflects anthropogenic $\mathrm{Hg}$ emissions prior to 1850 (section 2.5). Several long-term archives corroborate the importance of 

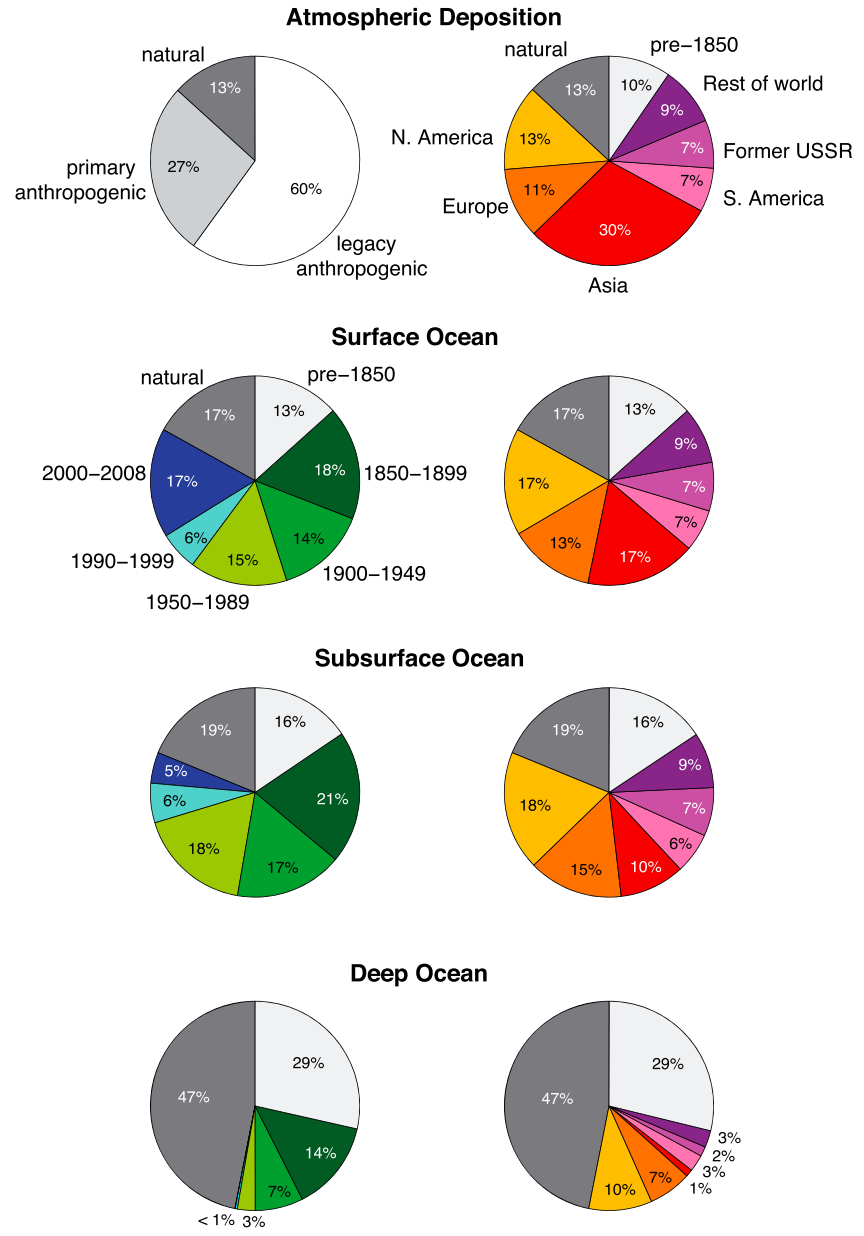

Figure 7. Natural and anthropogenic contributions to present-day atmospheric deposition and ocean reservoirs. The contribution from natural $\mathrm{Hg}$ is defined by steady state in our biogeochemical model without anthropogenic emissions. The primary anthropogenic contribution to deposition is from direct emissions (Figure 2a), while the legacy contribution is from anthropogenic $\mathrm{Hg}$ previously deposited and then re-emitted by surface reservoirs. The contribution from legacy $\mathrm{Hg}$ is calculated as total deposition minus primary anthropogenic emissions and natural emissions. For the ocean reservoirs, we partition the anthropogenic contribution by time period (left column) and region (right column). "Rest of world" includes Africa, the Middle East, and Oceania.

anthropogenic $\mathrm{Hg}$ emissions prior to 1850 [RoosBarraclough et al., 2002; Givelet et al., 2003; RoosBarraclough et al., 2006; Cooke et al., 2009, 2011; Thevenon et al., 2011; Conaway et al., 2012].

[33] Figure 7 gives the source contributions to present-day atmospheric deposition and oceanic reservoirs as computed from our model. Twenty-seven percent of atmospheric deposition is from primary anthropogenic emissions, which is consistent with previous estimates [Mason and Sheu, 2002; Selin et al., 2008; Pirrone et al., 1996, 2010; Corbitt et al., 2011]. We find that natural emissions contribute only $13 \%$ of present-day deposition when accounting for pre-1850 anthropogenic emissions. Sixty percent of present-day deposition is legacy anthropogenic $\mathrm{Hg}$ previously deposited and subsequently re-emitted. For the lower bound of anthropogenic emissions (section 3.3), 26\% of atmospheric deposition is from primary anthropogenic emissions, $57 \%$ is legacy, and $17 \%$ is natural. Past model studies had concluded that one third of present-day deposition is natural and one third is legacy anthropogenic, but this was built on the assumption of negligible anthropogenic emissions prior to 1850 and an imposed factor of 3 increase in deposition relative to 1850 based on sediment core data [Mason et al., 1994; Mason and Sheu, 2002; Seigneur et al., 2004; Selin et al., 2008]. Our results suggest that the contribution from natural emissions to present-day deposition is much smaller than is generally recognized and that the contribution from legacy anthropogenic emissions is correspondingly much larger. This result is sensitive to the magnitude of geogenic emissions (assumed here to be $90 \mathrm{Mg} \mathrm{a}^{-1}$ ), emphasizing the importance of improved estimates of these emissions.

[34] Figure 7 also shows the sensitivity of the present-day ocean reservoirs to anthropogenic emissions released in different historical periods. We find that $81 \%$ of the anthropogenic $\mathrm{Hg}$ in the deep ocean originates from pre-1900 emissions. This legacy $\mathrm{Hg}$ exerts a sustained effect on the surface and subsurface ocean, which is demonstrated by the result that pre-1950 anthropogenic emissions account for more than half of the present-day enrichment in the surface and subsurface reservoirs.

[35] Lastly, Figure 7 shows the contributions of post-1850 anthropogenic emissions from different source continents [from Streets et al., 2011] to the present-day anthropogenic enrichments of the different reservoirs. Although Asia presently accounts for $65 \%$ of global primary anthropogenic emissions [Streets et al., 2011], we find that $\mathrm{Hg}$ of Asian anthropogenic origin accounts for only $17 \%$ and $10 \%$ of the surface and subsurface ocean reservoirs, respectively. The legacy of past North American and European anthropogenic emissions together accounts for $24 \%$ of present-day deposition and $30 \%$ of surface ocean $\mathrm{Hg}$.

\section{Implications for the Future}

[36] We project future changes in the $\mathrm{Hg}$ cycle under four illustrative emission trajectories (section 2.5 and Figure 2a): (1) the business-as-usual A1B scenario of Streets et al. [2009] with continued increases in global emissions, (2) constant future emissions, (3) $50 \%$ decrease of emissions by 2050 ("mercury controls"), and (4) zero future anthropogenic emissions as a bounding case. These scenarios are assumed to take effect in 2015.

[37] Figure 2c shows the atmospheric deposition for each of the four future emission scenarios. Primary anthropogenic emissions increase by $2000 \mathrm{Mg} \mathrm{a}^{-1}$ between 2015 and 2050 under A1B, but atmospheric deposition increases by $4600 \mathrm{Mg} \mathrm{a}^{-1}$. Even if primary anthropogenic emissions stay constant between 2015 and 2050, atmospheric deposition increases by $30 \%$. Under these scenarios, new anthropogenic $\mathrm{Hg}$ is being added to the pool of legacy $\mathrm{Hg}$ faster than it can be sequestered into longer-lived reservoirs, and the legacy contribution to deposition grows as a result. Corbitt et al. [2011] projected that atmospheric deposition would remain at present-day levels under the B1 scenario of Streets et al. [2009] (effectively constant emissions), but they assumed the legacy $\mathrm{Hg}$ pool to remain constant. Our work 


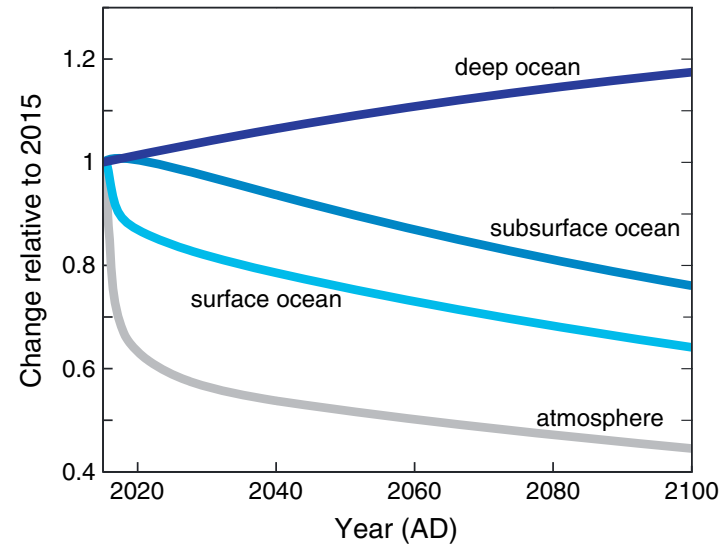

Figure 8. Change in reservoir masses relative to 2015 under a scenario of zero primary anthropogenic emissions after 2015.

highlights the importance of accounting for changing legacy $\mathrm{Hg}$ when modeling the future atmosphere.

[38] We find that a decrease in $\mathrm{Hg}$ emission is needed just to maintain $\mathrm{Hg}$ deposition at its present-day level. Under our hypothetical "mercury controls" scenario with 50\% decrease in primary anthropogenic emissions by 2050, deposition begins to decrease by 2020 as the legacy contribution stabilizes (reflecting a balance between new anthropogenic $\mathrm{Hg}$ inputs and transfer to the longer-lived reservoirs). In this scenario, primary emissions decrease by $1400 \mathrm{Mg} \mathrm{a}^{-1}$ from 2015 to 2050 while deposition decreases by $1200 \mathrm{Mg} \mathrm{a}^{-1}$. In the bounding case of zero future anthropogenic emissions, there is an immediate 30\% decrease in deposition (associated with primary anthropogenic emissions) and slower subsequent decrease limited by the timescale for transfer from the subsurface to the deep ocean (Figure 6).

[39] To illustrate the timescales required for dissipation of anthropogenic influence, Figure 8 shows the time-dependent responses of the atmosphere and ocean $\mathrm{Hg}$ reservoirs to complete elimination of anthropogenic $\mathrm{Hg}$ emissions from 2016 on. We previously pointed out the immediate $30 \%$ decrease in the atmosphere. There is also an immediate $10 \%$ decline in the surface ocean that is dampened relative to the atmosphere by the persistent legacy influence from the subsurface ocean. Subsequent decline in the surface ocean is more gradual, with $65 \%$ of the initial loading remaining in 2100 . The subsurface ocean begins to slowly decrease after a decade, mostly by transfer to the deep ocean, but the anthropogenic signal persists for centuries. The deep ocean reservoir continues to increase throughout the 21 st century even in the absence of primary anthropogenic emissions.

[40] Future $\mathrm{Hg}$ concentrations in the surface + subsurface ocean are of particular concern because they are critical for determining the reservoir available for oceanic methylmercury production [Mason et al., 2012] and associated concentrations in pelagic marine fish. Under the business-as-usual emissions trajectory, $\mathrm{Hg}$ concentrations in the combined surface + subsurface ocean will increase by $40 \%$ (relative to present day) by 2050 . Under the "mercury controls" scenario, the $\mathrm{Hg}$ concentration in the surface + subsurface will still increase by $20 \%$. Our results suggest that stabilization of ocean concentrations at present-day levels will require more aggressive reductions in primary anthropogenic emissions than is usually recognized.

\section{Conclusions}

[41] We have developed a seven-compartment biogeochemical box model to describe the global cycling of mercury $(\mathrm{Hg})$ between the atmosphere, ocean, and terrestrial reservoirs. The model is based on our best current understanding from observations and process models and is described by first-order rate constants ordinary differential equations (coupled ODEs) for the transfer of $\mathrm{Hg}$ between compartments. We forced the model with time-dependent historical emissions (2000 BC-present), initializing from natural steady state, and showed consistency with observational constraints for the present-day budget and anthropogenic enrichments. We used the model to analyze the timescales involved in $\mathrm{Hg}$ cycling and to quantify the impact of legacy anthropogenic $\mathrm{Hg}$ in the present-day global budget and under various future emission scenarios.

[42] We find that characteristic timescales for $\mathrm{Hg}$ global biogeochemical cycling range from less than a year for coupling between the subsurface/surface ocean and the atmosphere to thousands of years for transfer from the armored soil to the deep mineral pool via the deep ocean. The subsurface ocean, extending from the base of the ocean mixed layer down to the permanent thermocline, plays a central role in the global biogeochemical cycling of $\mathrm{Hg}$. A perturbation to the surface reservoirs (atmosphere, ocean, and fast terrestrial) propagates to the subsurface ocean on a timescale of years to decades and persists there for decades to centuries. Under natural conditions, terrestrial reservoirs contain a larger $\mathrm{Hg}$ inventory than the ocean. However, perturbations to surface reservoirs first propagate to the deep ocean because transfer of $\mathrm{Hg}$ to the armored soil reservoir is extremely slow and persist in the deep ocean for centuries to millennia with upwelling causing a sustained effect on the surface and subsurface ocean. The persistence of $\mathrm{Hg}$ in the ocean is of particular environmental consequence because of the importance of marine fish as source of methylmercury exposure for humans and wildlife.

[43] Atmospheric deposition in the model increases by a factor of 2.6 from 1840 to present, consistent with sediment archives. This factor of 3 has been regarded in previous studies as the anthropogenic enrichment relative to natural conditions, but in fact, the anthropogenic perturbation to the $\mathrm{Hg}$ cycle extends back for millennia. We find that alltime anthropogenic $\mathrm{Hg}$ emissions have enriched the present-day atmosphere, surface ocean, and deep ocean by factors of 7.5, 5.9, and 2.1, respectively, relative to natural conditions. This is a much larger relative anthropogenic perturbation than is usually recognized.

[44] Model results show that most $(60 \%)$ of present-day $\mathrm{Hg}$ atmospheric deposition is legacy anthropogenic $\mathrm{Hg}$ re-emitted from surface reservoirs. Natural emissions and primary anthropogenic emissions contribute $13 \%$ and $27 \%$ to present-day deposition, respectively. Over half of the anthropogenic enrichment of the surface ocean is from pre1950 emissions, and most of the anthropogenic enrichment of the deep ocean is from pre-1900 emissions. Although Asia accounts for $65 \%$ of present-day primary anthropogenic emissions [Streets et al., 2011], $\mathrm{Hg}$ of Asian 
anthropogenic origin only accounts for 30\% of present-day atmospheric deposition and $17 \%$ of the surface ocean reservoir. By contrast, North America and Europe together account for $30 \%$ of the surface ocean reservoir.

[45] Understanding how the legacy of past anthropogenic emissions contributes to present-day $\mathrm{Hg}$ enrichment is essential for anticipating the effectiveness of future $\mathrm{Hg}$ emission reduction strategies. If anthropogenic emissions continue to rise, the resulting growth in atmospheric deposition will be greater than the increase in primary emissions due to sustained growth of the legacy component. Even if emissions stay constant, atmospheric deposition will continue to increase because new anthropogenic $\mathrm{Hg}$ will add to the surface + subsurface ocean reservoir faster than $\mathrm{Hg}$ can be transferred from that reservoir to the deep ocean. Our work shows that projecting future atmospheric deposition under changing emissions requires a full accounting of the coupling between the biogeochemical reservoirs. Aggressive reduction in primary anthropogenic emissions will be needed just to maintain oceanic $\mathrm{Hg}$ concentrations at present-day levels.

[46] We investigated the response of the global $\mathrm{Hg}$ cycle to zeroing primary anthropogenic emissions after 2015 as a bound on the maximum global benefits to be expected from regulating emissions. We find a nearly instantaneous 30\% decrease in atmospheric deposition and 10\% decrease in the surface ocean reservoir. Subsequent declines are slower, limited by the timescale for transfer to the deep ocean. By 2100 , there is a $55 \%$ decrease in atmospheric deposition and $35 \%$ decrease in surface ocean loading. The subsurface ocean responds more slowly to the elimination of primary anthropogenic emissions and, by 2100 , has decreased by $25 \%$.

[47] Our analysis has focused on the global background. However, Hg concentrations in the surface ocean and terrestrial reservoirs vary depending on local environmental conditions, and many historic $\mathrm{Hg}$ problems have occurred as site-specific contamination issues from point sources. Ecosystem-scale studies indicate large variability in biotic $\mathrm{Hg}$ response to total $\mathrm{Hg}$ loading, depending on conditions facilitating methylmercury production [Harris et al., 2007; Knightes et al., 2009]. The global information provided here needs to be combined with site-specific understanding of the factors driving biological exposures.

[48] Our analysis points to the need for improved, empirically constrained estimates of ocean evasion, geogenic emissions, and primary anthropogenic emissions. Whether or not organic carbon serves as the best analogue for modeling terrestrial $\mathrm{Hg}$ cycling also deserves further investigation. Ocean evasion and terrestrial cycling influence the fate and accumulation of $\mathrm{Hg}$. Geogenic emissions determine the natural environmental burden of $\mathrm{Hg}$ and hence the impact of all-time anthropogenic $\mathrm{Hg}$ emissions, which may also be inferred from multimillennia sedimentary records. Improved estimates of these quantities will allows us to better estimate the impact of present-day and future anthropogenic $\mathrm{Hg}$ emissions and more confidently establish the effectiveness of implemented regulation.

[49] Acknowledgments. We thank Jeroen Sonke and an anonymous reviewer for their thoughtful comments. We acknowledge financial support from NSF Atmospheric Chemistry (ATM0961357), NSF Chemical Oceanography (OCE1130549), and the Electric Power Research Institute (EPRI).
H.M.A. acknowledges support from NSF GRFP. We thank Anne Soerensen and Mauricio Santillana for thoughtful discussions.

\section{References}

Amos, H. M., et al. (2012), Gas-particle partitioning of atmospheric $\mathrm{Hg}$ (II) and its effect on global mercury deposition, Atmos. Chem. Phys., 12(1), 591-603.

Andren, M. O., and J. O. Nriagu (1979), The global cycle of mercury, in Biogeochemistry of Mercury in the Environment, edited by J. O. Nriagu, pp. 1-15, Elsevier, Amsterdam.

Antia, A. N., et al. (2001), Basin-wide particulate carbon flow in the Atlantic Ocean: Regional export patterns and potential for atmospheric $\mathrm{CO}_{2}$ sequestration, Global Biogeochem. Cycles, 15(4), 845-862.

Bagnato, E., et al. (2011), New clues on the contribution of Earth's volcanism to the global mercury cycle, Bull. Volcanol., 73(5), 497-510.

Biester, H., et al. (2007), Modeling the past atmospheric deposition of mercury using natural archives, Environ. Sci. Technol., 41(14), 4851-4860.

Camargo, J. A. (2002), Contribution of Spanish-American silver mines (1570-1820) to the present high mercury concentrations in the global environment: A review, Chemosphere, 48(1), 51-57.

Conaway, C. H., et al. (2012), Recent paleorecords document rising mercury contamination in Lake Tanganyika, Appl. Geochem., 27(1), 352-359.

Cooke, C. A., et al. (2009), Over three millennia of mercury pollution in the Peruvian Andes, Proc. Natl. Acad. Sci. U. S. A., 106(22), 8830-8834.

Cooke, C. A., et al. (2011), Pre-Colombian mercury pollution associated with the smelting of argentiferous ores in the Bolivian Andes, Ambio, $40(1), 18-25$.

Corbitt, E. S., et al. (2011), Global source-receptor relationships for mercury deposition under present-day and 2050 emissions scenarios, Environ. Sci. Technol., 45(24), 10477-10484.

Drevnick, P. E., et al. (2012), Spatial and temporal patterns of mercury accumulation in lacustrine sediments across the Laurentian Great Lakes region, Environ. Pollut., 161, 252-260.

Elbaz-Poulichet, F., et al. (2011), A 3500-year record of $\mathrm{Hg}$ and $\mathrm{Pb}$ contamination in a Mediterranean sedimentary archive (The Pierre Blanche Lagoon, France), Environ. Sci. Technol., 45(20), 8642-8647.

Ferrara, R., et al. (2000), Volcanoes as emission sources of atmospheric mercury in the Mediterranean basin, Sci. Total Environ., 259(1-3), $115-121$.

Fitzgerald, W. F., et al. (1998), The case for atmospheric mercury contamination in remote areas, Environ. Sci. Technol., 32(1), 1-7.

Friedli, H. R., et al. (2009), Initial estimates of mercury emissions to the atmosphere from global biomass burning, Environ. Sci. Technol., 43(10), 3507-3513.

Gill, G. A., and W. F. Fitzgerald (1988), Vertical mercury distributions in the ocean, Geochim. Cosmochim. Acta, 52(6), 1719-1728.

Givelet, N., et al. (2003), Predominant anthropogenic sources and rates of atmospheric mercury accumulation in southern Ontario recorded by peat cores from three bogs: comparison with natural "background" values (past 8000 years), J. Environ. Monit., 5(6), 935-949.

Goldwater, L. (1972), Mercury: A history of quicksilver, Pages 32-55, 72-83, York Press, Baltimore, MD.

Harris, R. C., et al. (2007), Whole-ecosystem study shows rapid fishmercury response to changes in mercury deposition, Proc. Natl. Acad. Sci. U. S. A., 104(42), 16586-16591.

Holmes, C. D., et al. (2010), Global atmospheric model for mercury including oxidation by bromine atoms, Atmos. Chem. Phys., 10, 12037-12057.

Johansen, P., et al. (2004), Human exposure to contaminants in the traditional Greenland diet, Sci. Total Environ., 331(1-3), 189-206.

Kim, N. S., and B. K. Lee (2010), Blood total mercury and fish consumption in the Korean general population in KNHANES III, 2005, Sci. Total Environ., 408(20), 4841-4847.

Knightes, C. D., et al. (2009), Application of ecosystems-scale fate and bioaccumulation models to predict fish mercury response times to changes in atmospheric deposition, Environ. Toxicol. Chem., 28(4), $881-893$.

Lacerda, L. D. (1997), Global mercury emissions from gold and silver mining, Water Air Soil Pollut., 97(3-4), 209-221.

Lamborg, C. H., et al. (2002a), Modern and historic atmospheric mercury flows in both hemispheres: Global and regional mercury cycling implications, Global Biogeochem. Cycles, 16(4), 1104, doi:10.1029/ $2001 \mathrm{~GB} 001847$.

Lamborg, C. H., et al. (2002b), A non-steady-state compartmental model of global-scale mercury biogeochemistry with interhemispheric atmospheric gradients, Geochim. Cosmochim. Acta, 66(7), 1105-1118. 


\section{AMOS ET AL.: GLOBAL IMPACTS OF LEGACY MERCURY}

Lindberg, S., et al. (2007), A synthesis of progress and uncertainties in attributing the sources of mercury in deposition, Ambio, 36(1), 19-32.

Lindqvist, O., and H. Rodhe (1985), Atmospheric mercury - A review, Tellus B Chem. Phys. Meteorol., 37(3), 136-159.

Mason, R. P., and G. R. Sheu (2002), Role of the ocean in the global mercury cycle, Global Biogeochem. Cycles, 16(4), 1093, doi:10.1029/ 2001GB001440.

Mason, R. P., et al. (1994), The biogeocheical cycling of elemental mercury - anthropogenic influences, Geochim. Cosmochim. Acta, 58 (15), 3191-3198.

Mason, R. P., et al. (2012), Mercury biogeochemical cycling in the ocean and policy implications, Environ. Res., 119, 101-117.

Montegut, C. D., et al. (2004), Mixed layer depth over the global ocean: An examination of profile data and a profile-based climatology, J. Geophys. Res., 109, C12003, doi:10.1029/2004JC002378.

Nakicenovic, N. (2000), Greenhouse gas emissions scenarios, Technol. Forecast. Soc. Change, 65(2), 149-166.

Nriagu, J. O. (1979), Production and uses of mercury, in Biogeochemistry of Mercury in the Environment, edited by M. O. Andren and J. O. Nriagu, pp. 23-39, Elsevier, Amsterdam.

Nriagu, J. O. (1993), Legacy of mercury pollution, Nature, 363(6430), 589.

Nriagu, J. O. (1994), Mercury pollution from the past mining of gold and silver in the Americas, Sci. Total Environ., 149(3), 167-181.

Nriagu, J., and C. Becker (2003), Volcanic emissions of mercury to the atmosphere: Global and regional inventories, Sci. Total Environ., 304(1-3), 3-12.

Pacyna, J. M., et al. (2003), Mapping 1995 global anthropogenic emissions of mercury, Atmos. Environ., 37, S109-S117.

Pacyna, E. G., et al. (2006), Global anthropogenic mercury emission inventory for 2000, Atmos. Environ., 40(22), 4048-4063.

Pacyna, E. G., et al. (2010), Global emission of mercury to the atmosphere from anthropogenic sources in 2005 and projections to 2020, Atmos. Environ., 44(20), 2487-2499.

Parrella, J. P., et al. (2012), Tropospheric bromine chemistry: implications for present and pre-industrial ozone and mercury, Atmos. Chem. Phys. 12(15), 6723-6740.

Pirrone, N., et al. (1996), Regional differences in worldwide emissions of mercury to the atmosphere, Atmos. Environ., 30(17), 2981-2987.

Pirrone, N., et al. (2010), Global mercury emissions to the atmosphere from anthropogenic and natural sources, Atmos. Chem. Phys., 10(13), 5951-5964.

Potter, C. S., et al. (1993), Terrestrial ecosystem production - A process model-based on global satellite and surface data, Global Biogeochem Cycles, 7(4), 811-841.

Prather, M. J. (1996), Timescales in atmospheric chemistry: Theory, GWPs for $\mathrm{CH} 4$ and $\mathrm{CO}$, and runaway growth, Geophys. Res. Lett., 23(19), 2597-2600.

Pyle, D. M., and T. A. Mather (2003), The importance of volcanic emissions for the global atmospheric mercury cycle, Atmos. Environ. $37(36), 5115-5124$

Qureshi, A., et al. (2011), Quantifying uncertainties in the global mass balance of mercury, Global Biogeochem. Cycles, 25, GB4012, doi:10.1029/2011GB004068.

Roos-Barraclough, F., et al. (2002), A 14500 year record of the accumulation of atmospheric mercury in peat: Volcanic signals, anthropogenic influences and a correlation to bromine accumulation, Earth Planet. Sci. Lett., 202(2), 435-451.

Roos-Barraclough, F., et al. (2006), Use of $\mathrm{Br}$ and $\mathrm{Se}$ in peat to reconstruct the natural and anthropogenic fluxes of atmospheric $\mathrm{Hg}$ : A 10000-year record from Caribou Bog, Maine, Environ. Sci. Technol., 40(10), 3188-3194.

Schuster, P. F., et al. (2002), Atmospheric mercury deposition during the last 270 years: A glacial ice core record of natural and anthropogenic sources, Environ. Sci. Technol., 36(11), 2303-2310.

Seigneur, C., et al. (2004), Global source attribution for mercury deposition in the United States, Environ. Sci. Technol., 38(2), 555-569.

Selin, N. E., et al. (2008), Global 3-D land-ocean-atmosphere model for mercury: Present-day versus preindustrial cycles and anthropogenic enrichment factors for deposition, Global Biogeochem. Cycles, 22, GB3099, doi:10.1029/2007GB003040.

Shia, R. L., et al. (1999), Global simulation of atmospheric mercury concentrations and deposition fluxes, J. Geophys. Res., 104(D19), 23747-23760.

Slemr, F., et al. (1985), Distribution, speciation, and budget of atmospheric mercury, J. Atmos. Chem., 3(4), 407-434.

Smith-Downey, N. V., et al. (2010), Anthropogenic impacts on global storage and emissions of mercury from terrestrial soils: Insights from a new global model, J. Geophys. Res., 115, G03008, doi:10.1029/ 2009JG001124.

Soerensen, A. L., et al. (2010), An improved global model for air-sea exchange of mercury: High concentrations over the North Atlantic, Environ. Sci. Technol., 44(22), 8574-8580.

Soerensen, A. L., et al. (2012), Multi-decadal decline of mercury in the North Atlantic atmosphere explained by changing subsurface seawater concentrations, Geophys. Res. Lett., 39, L21810, doi:10.1029/ 2013GL053736.

Streets, D. G., et al. (2009), Projections of global mercury emissions in 2050, Environ. Sci. Technol., 43(8), 2983-2988

Streets, D. G., et al. (2011), All-time releases of mercury to the atmosphere from human activities, Environ. Sci. Technol., 45(24), 10485-10491.

Sunderland, E. M. (2007), Mercury exposure from domestic and imported estuarine and marine fish in the US seafood market, Environ. Health Perspect., 115(2), 235-242.

Sunderland, E. M., and R. P. Mason (2007), Human impacts on open ocean mercury concentrations, Global Biogeochem. Cycles, 21, GB4022, doi:10.1029/2006GB002876.

Thevenon, F., et al. (2011), (Pre-) historic changes in natural and anthropogenic heavy metals deposition inferred from two contrasting Swiss Alpine lakes, Quat. Sci. Rev., 30(1-2), 224-a233.

Thompson, A. M., et al. (1993), The atmospheric $\mathrm{CH}_{4}$ increase since the Last Glacial Maximum. 2. Interactions with oxidants, Tellus $B$ Chem. Phys. Meteorol.., 45(3), 242-257.

United Nations Environment Program (UNEP) (2013), http://www.iisd.ca/ mercury/inc5/, 08 February 2013.

Varekamp, J. C., and P. R. Buseck (1986), Global mercury flow from volcanic and geothermal sources, Appl. Geochem., 1(1), 65-73.

van der Werf, G. R., et al. (2003), Carbon emissions from fires in tropical and subtropical ecosystems, Glob. Change Biol., 9(4), 547-562.

$\mathrm{Wu}, \mathrm{Y}$., et al. (2006), Trends in anthropogenic mercury emissions in China from 1995 to 2003, Environ. Sci. Technol., 40(17), 5312-5318. 